\title{
Comparison of PCR fingerprinting techniques for the discrimination of Salmonella enterica subsp. enterica serovar Weltevreden isolated from indigenous vegetables in Malaysia.
}

\begin{abstract}
Salmonella enterica subsp. enterica (S.) serovar Weltevreden has emerged as a public health problem in many countries. Genomic DNA of S. Weltevreden from indigenous vegetables namely 'selom' (Oenanthe stolonifera), 'pegaga' (Centella asiatica), 'kesum' (Polygonum minus) and 'kangkong' (Ipomoea aquatica) were characterized by duplex-polymerase chain reaction (duplex-PCR), multiplex-polymerase chain reaction (multiplex-PCR), random amplified polymorphic DNA (RAPD), enterobacterial repetitive intergenic consensuspolymerase chain reaction (ERIC-PCR) and polymerase chain reaction-restriction fragment length polymorphism (PCR-RFLP). The results demonstrated that a total of four clusters and three single isolates were generated from ERIC-PCR with primers ERIC-1 and ERIC-2 whereas RAPD with arbitrary primers OPAR2, OPAR17 and OPAR19 discriminated the S. Weltevreden into nine clusters and eight single isolates at a common 65\% similarity level with discriminatory index (D) of 0.7443 and 0.9394 respectively. Composite analysis of banding profiles generated from RAPD-PCR and ERIC-PCR showed eight clusters and six single isolates at $65 \%$ similarity level with the highest $\mathrm{D}$ value that is 0.9508 . On the other hand, PCR-RFLP and duplex PCR data exhibited a consistent profile for S. Weltevreden. Multiplex-PCR targeting three different antibiotic resistance genes and a common Salmonella specific gene segment produced two distinguishing profiles among the S. Weltevreden examined. These results demonstrated that the combined analysis of RAPD-PCR and ERICPCR is a better tool for characterizing S. Weltevreden than individual methods.
\end{abstract}

Keyword: Duplex-PCR; ERIC-PCR; Indigenous vegetables; Multiplex-PCR; PCR-RFLP; RAPD; S. Weltevreden. 